The International Journal of Digital Accounting Research

Vol. 8, N. 14, 2008, pp. 81-96

ISSN: $1577-8517$

\title{
An Empirical Examination of Competing Theories to Explain Continuous Disclosure Technology Adoption Intentions Using XBRL as the Example Technology
}

\author{
Robert Pinsker. Old Dominion University. Norfolk, VA. USA. \\ rpinsker@odu.edu
}

\begin{abstract}
The purpose of this paper is to test competing theories from Pinsker's (2007) new research framework in order to provide a better understanding of XBRL (as the continuous disclosure technology example) adoption intentions of managers who have low knowledge of XBRL, but work for firms who may adopt. A survey methodology was used with experienced business professionals and MBA students. Two of three research propositions were empirically supported. The results indicate that both the technology acceptance model (TAM) and absorptive capacity represent appropriate theories for studying XBRL adoption. However, future related TAM research should be conducted either with a modified 'attitude' variable or through eliminating this variable altogether.
\end{abstract}

Results provide an empirical validation of part of Pinsker's (2007) framework. The findings add to the existing practical and academic literature regarding perceived benefits of XBRL adoption for firms. The difference in significance between TAM variables represents a unique finding in the TAM literature, which suggests XBRL adoption has significantly different aspects than previous information technology adoption research in general. Future research opportunities are explored.

Key words: XBRL adoption, continuous disclosure, TAM, absorptive capacity. 


\section{INTRODUCTION}

In today's dynamic business environment, there are an increasing amount of calls for more frequent firm disclosure (i.e., reporting both financial and nonfinancial information) to ensure investors, lenders, and regulators have access to timely information to make informed decisions (Hunton et al. 2003). Regulatory bodies around the globe have begun to increase the timeliness of disclosure requirements for public firms, (e.g., section 409 of the Sarbanes-Oxley Act (SOX; 2002) in the U.S. and continuous disclosure initiatives in Australia). Disclosures made to regulators in many countries are typically public information (e.g., Form 8-K in the U.S.); thus, the disclosures are also viewed by investors. Management, therefore, needs to consider an information technology (IT) that is capable of complying with the reporting regulatory requirements as well as one that is useful to investors for analyzing firm information (for cost of equity capital considerations).

Pinsker's (2007) conceptual paper provides a theoretical framework for studying continuous disclosure (CD) technology adoption using XBRL (eXtensible Business Reporting Language) as the example technology ${ }^{1}$. Based on Fichman's (1992) theory of multi-level research and Li et al.'s (2004) governance theory, Pinsker makes research propositions investigating XBRL adoption intentions using two theories from both the individual decision level and the organizational/firm level. He claims that other than a few mandated instances, there is global uncertainty regarding $\mathrm{CD}$ technology adoption that needs to be explored. The uncertainty exists despite the empirical benefits of XBRL adoption found in previous academic literature for firms (Bonson 2001; Pinsker and Li forthcoming; Pinsker and Wheeler 2003) and investors (Hodge et al. 2004; Pinsker and Wheeler 2003). Accordingly, the purpose of this paper is to be the first to empirically test Pinsker's conceptual framework by examining management's XBRL (as the CD technology example) adoption intentions in order to determine which theory is the most appropriate ${ }^{2}$. The Technology Acceptance Model (TAM) and absorptive capacity were chosen specifically due to their wider acceptance in the IT literature.

\footnotetext{
${ }^{1}$ Recognizing the ambiguity of the term, "continuous" disclosure is broadly defined in the context of the applicable domestic regulation. Thus, no single definition is used.

${ }^{2} \mathrm{XBRL}$ is the example used because it: 1) has a global consortium of over 400 practitioners, firms, and regulators as members and 2) is a leading technology involved in disclosure-related regulation. For example, the Securities
} 
This study conducted a survey using MBA students and business professionals in the U.S. The participants proxied for mid-level managers who are involved in making the CD technology adoption decision. Survey results indicate both the TAM and absorptive capacity theories are able to predict XBRL adoption intentions. However, the TAM regression result was able to explain slightly more of the variation. T-tests showed participants believed XBRL would be relatively easy to learn for their jobs (absorptive capacity); it was useful for their jobs (TAM), and they had favorable attitudes toward technology in general (TAM). An interesting result occurred when the research proposition for perceived usefulness was supported, but the proposition for attitude toward technology was not. This finding is unique in the TAM literature. The finding reinforces Pinsker's (2007) argument that research on XBRL adoption can be differentiated from prior IT adoption research.

The process of IT adoption is critical in deriving the benefits of IT (Karahanna et al. (1999). Yet, there have been few IT studies that have separated pre-adoption and post-adoption behavior. The current study contributes to the IT literature (specifically, that related to XBRL) by providing a greater understanding as to why managers may want to adopt a CD technology. Specifically, it builds off of a recent conceptual framework by including empirical evidence that both the TAM and absorptive capacity represent appropriate theories to design a field study or experiment regarding CD technology (or more particularly, XBRL) adoption research. This stream of research is important for U.S. firms and the Securities and Exchange Commission (SEC), given the large number of firms potentially affected by the SEC's XBRL voluntary filing program, as well as for firms and regulators outside of the U.S. involved in similar regulatory projects ${ }^{3}$

The next section reviews Pinsker's (2007) conceptual framework relevant to this paper. A discussion of the survey methodology used follows. Survey results are

and Exchange Commission initiated an XBRL voluntary filing program as an attempt to make firm disclosures more interactive, as well as to assist firms in complying with SOX (2002) section 409's four day disclosure requirement (for material events). Additionally, XBRL could be used to generate internal benefits for management (i.e., through the use of XBRL Global Ledger); however, the focus of this paper is exclusively on XBRL for external financial reporting purposes.

${ }^{3}$ Comments made in the popular press (most notably The Wall Street Journal) have indicated that the SEC could mandate XBRL use as soon as the fourth quarter of 2008. 
presented next, with the conclusions, limitations, and future research opportunities discussed at the end.

\section{THEORY AND RESEARCH HYPOTHESES}

\section{Theoretical Framework}

Pinsker (2007) based his framework upon two distinct theoretical models. Fichman (1992) reviewed a significant portion of IT adoption and diffusion research at the time and created a theoretical model that expands classical diffusion theory. His model uses four cells and classifies the existing research according to its locus of adoption (i.e., individual or firm) and class of technology (i.e., the levels of knowledge burden and user interdependencies). Since the current paper is concerned with only one type of technology, that which is capable of enabling CD, the class of technology is constant. Therefore, the only part of Fichman's model being applied is the locus of adoption.

Fichman's (1992) locus of adoption concept can be expanded to a macro level. Li et al's (2004) theoretical model claims IT adoption tendencies in various countries are based on corporate governance for that country. They state that when a country is governed by transparent, fair, and universally applied rule of law, it is called a rule-based country. The U.S. is an example. Consequently, when a country has unfair public rules with a general lack of rule of law, its citizens have to rely on relationships to conduct their business. This is called a relation-based country, of which China is an example.

Li et al.'s (2004) theoretical model relates to Fichman's (1992) locus of control by indicating rule-based countries typically have a decentralized IT decisionmaking process in which a pool of individuals may make the final adoption decision; whereas, relation-based countries are characterized by a highly centralized decision-making process where typically one individual makes the adoption decision. The exception to rule-based countries using a decentralized process is for small firms. According to Fichman, smaller U.S. firms in particular are characterized by more centralized and autonomous decision-making. Pinsker's (2007) framework is depicted in table 1. 


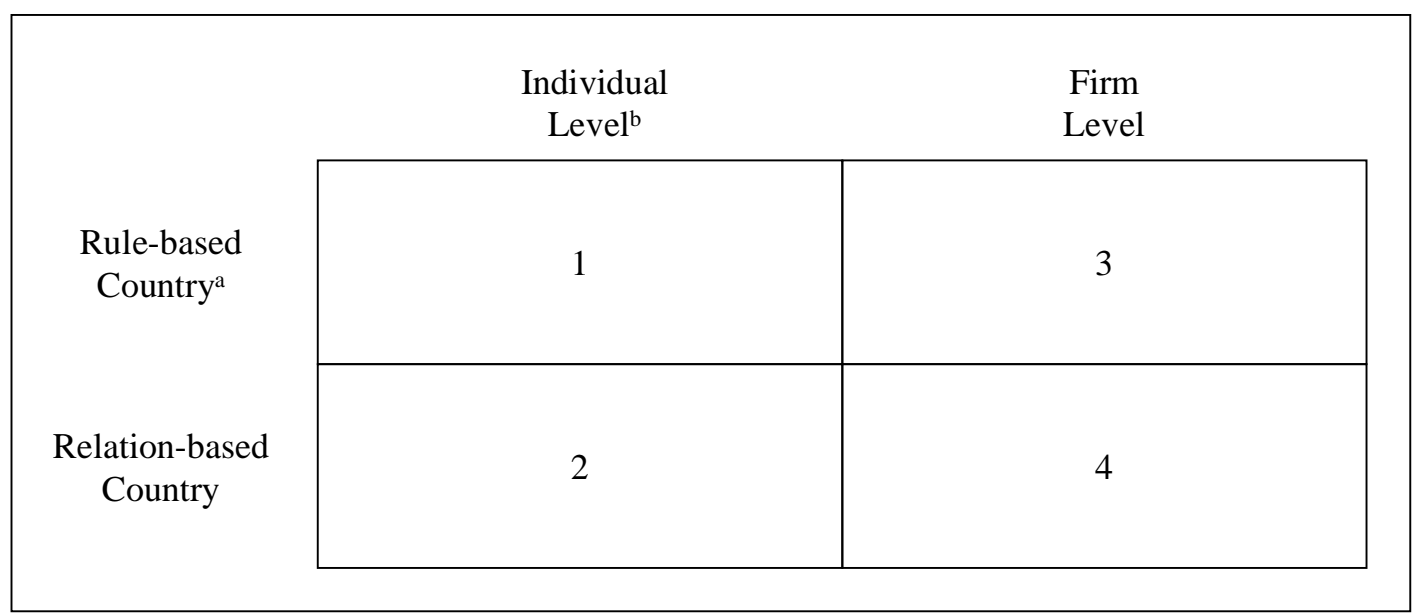

Table 1. Pinsker's (2007) Framework

a Represents Li et al.'s (2004) theory of corporate governance. Rule-based countries have well defined and enforceable rules that businesses rely on as a cornerstone. The U.S. is an example. Relation-based countries do not have enforceable rules, but are governed more through relations between business people and individuals in government. China is an example.

b Represents the part of Fichman's (1992) model applied in Pinsker's (2007) framework. Specifically, it refers to either the individual or firm-level decision making process. It should be noted that the "other" part of Fichman's model, level of user interdependency, is held constant for this framework.

\section{Technology Acceptance Model (TAM)}

Al-Gahtani (2001) indicated a major focus of Information Systems innovation research has been how potential users' perceptions of an IT influence its adoption. User acceptance has typically been a critical factor determining the success of an IT adoption (e.g., Attewell and Rule 1984; Davis 1993). The TAM captures an individual's (i.e., manager's) intention to accept/adopt an IT, as compared to Diffusion of Innovation (DOI) theory's emphasis on existing system usage. Several previous TAM studies have shown that intention to adopt an IT is highly correlated with actual adoption (see Pinsker and Wheeler (2003) for a review). Further, AlGahtani provides empirical evidence supporting the TAM's use for firms outside of North America. Thus, the TAM appears to provide an appropriate theoretical model for measuring management's $\mathrm{CD}$ technology pre-adoption decision-making process when the decision is an individual one.

A major purpose of the TAM is to provide a theoretical basis for understanding the impact of external factors on internal beliefs and attitudes (Al-Gahtani 2001). It uses perceived usefulness and attitudes toward technology adoption as its key 
variables to predict IT adoption ${ }^{4}$. Pinsker (2007) proposes that if the individual making the adoption decision possesses high levels of perceived usefulness and has a favorable attitude toward technology, that individual's firm will be likely to adopt XBRL. Thus, the first two hypotheses are:

- Hypothesis 1: XBRL adoption will result if the adoption decision maker has a high level of perceived usefulness toward the technology.

- Hypothesis 2: XBRL adoption will result if the adoption decision maker has a favorable attitude toward XBRL and in technology in general.

\section{Absorptive Capacity}

Absorptive capacity refers to a firm's ability to evaluate and utilize outside knowledge (Cohen and Levinthal 1990). Specifically, absorptive capacity measures a firm's ability to absorb, assimilate, and exploit an innovation throughout a firm (Link and Siegel 2002). Managers must be able to learn how to use the technology in order for it to be successfully adopted. Pinsker (2007) implies that the easier a technology is to learn, if there is a need for it, the more likely the firm would adopt it.

The absorptive capacity construct has been extensively investigated at a conceptual level, with little empirical verification (Kim 1998; Koza and Lewin 1998). Therefore, the role of absorptive capacity has not been verified across different firm contexts (George et al. 2001). The little empirical work that has been conducted typically used high technology firms and a single methodology and measure ${ }^{5}$. Specifically, archival data regarding research and development "intensity" for high technology firms has been the predominate design to study absorptive capacity. In addition to use of a single measure, a significant limitation to this prior research has been the use of firms who are typically early adopters of a new technology. The results are, therefore, expected that these firms would possess the capabilities to quickly acquire and assimilate new technologies, primarily

\footnotetext{
${ }^{4}$ Perceived ease of use is also a variable in the TAM, but research has shown it is only indirectly related to IT acceptance (Davis 1993). When perceived usefulness is measured together with perceived ease of use, the latter variable has an antecedent effect on IT acceptance. Therefore, consistent with Pinsker's (2007) recommendation, it is excluded for testing the related hypotheses.

${ }^{5}$ Using a singular methodology represents a lack of triangulation and robustness; while single measures also limit the robustness of the findings, as well as providing an opportunity for bias in variable selection.
} 
because managers of these firms can relatively easily learn the technology (Stock et al. 2001).

Link and Siegel (2002) construct a field study examining the effect of a new technology on labor unions. They assert that a field study investigation of absorptive capacity is a reasonable alternative to a more systematic analysis, because it allows researchers to assess the impact of a specific technology either for a given industry or across industries depending on the specific design employed. Through their unique (for absorptive capacity research) methodology, Link and Siegel were able to create multiple measures for absorptive capacity and study a firm that was not in the high technology industry.

The most interesting subunit of potential XBRL (as the CD technology example) adopters is the non-high technology firms. Whereas the majority of high technology firms are already XBRL supporters and early adopters (e.g., Microsoft), the firms not in high technology industries elicit slower adoption tendencies since they are not currently required to adopt XBRL. These more traditional, non-high technology firms also make up the majority of public firms in the U.S. Therefore, research on their XBRL adoption intentions is not only magnified, but also comes with no a priori predictions (i.e., there is a high level of uncertainty).

Pinsker's (2007) proposition related to absorptive capacity predicts a positive relationship between a firm's absorptive capacity levels and intention to adopt. Therefore, the current study's third hypothesis is:

- Hypothesis 3: Absorptive capacity levels will be positively related to the decision to adopt XBRL.

\section{METHODOLOGY}

\section{Research Design}

The following information relates the current study's design to Pinsker's (2007) conceptual framework depicted in table 1. The survey was conducted in the U.S., a rule-based country, using individuals from various sized firms. No managers from international firms were used. Analysis of the results is thus limited to boxes one and three from table 1. However, large U.S. firms tend to decentralize IT adoption decisions; whereas, international firms from relation-based countries 
(e.g., China; Li et al. 2004) and smaller U.S. firms tend to make centralized IT adoption decisions (Fichman 1992). Therefore, the particular sample used (including individuals from both large and small U.S. firms) justifies the use of Pinsker's joint individual-level and firm-level decision-making framework.

The target population for this survey was mid-level managers who had little or no previous XBRL knowledge (as a proxy for managers from the non-high technology firms). Two samples of participants were used to try and capture this population. The first sample, business professionals, were obtained at an all-day continuing professional education seminar. The survey was given out after an hour long presentation of basic XBRL concepts. The information presented was obtained from the XBRL Web site (www.XBRL.org) and, thus, was public knowledge. No attempts at XBRL advocacy were made during the presentation. Participation in the study was voluntary and the responses were anonymous.

17 out of a possible 34 business professionals (a 50\% success rate) completed the survey and returned it at the end of the day. Given the lack of incentives to participate, as well as the limited time during lunch and snack breaks to complete the survey, the $50 \%$ success rate compares favorably to similar survey research. The average (standard deviation) age of these participants was 42.53 years (11.41). There were nine females (53\%) and eight males (47\%) that completed the survey. The sample had an average (standard deviation) of 17.56 (11.15) years of professional work experience. Finally, they had very low knowledge and experience with XBRL prior to the presentation. Their means (standard deviations) of 1.71 (1.36) and 1.24 (0.66) for XBRL knowledge and experience, respectively, were captured on seven-point Likert scales where $1=$ not very knowledgeable/ inexperienced, $4=$ somewhat knowledgeable/experienced, and $7=$ very knowledgeable/ experienced. Thus, this sample appeared to fit the target population of managers with low levels of previous XBRL knowledge and experience.

The second sample involved MBA students who were finishing up their degree programs and were enrolled in an Accounting course. The MBA students were given the same brief XBRL presentation as the business professionals and were asked to voluntarily complete the survey. Since the surveys were anonymous, no extra credit or form of incentive was given to the students. All 61 students completed a usable survey (100\% success rate). 
The average (standard deviation) age of the MBA student participants was 27.90 years (4.61). There were 26 females (43\%), 34 males (56\%), and 1 nonrespondent $(1 \%)$ that completed the survey. They had an average (standard deviation) of 6.04 (4.85) years of professional work experience. Finally, they had very low knowledge and experience with XBRL prior to the presentation. Their means (standard deviations) of 1.49 (1.22) and 1.44 (1.20) for XBRL knowledge and experience, respectively, were captured on the same seven-point Likert scales as those used for the business professionals.

\section{Variables}

\section{Dependent Variable}

The dependent variable of interest was 'intent to adopt XBRL' (as the CD example technology). The five initial measures for this variable were adapted from Link and Siegel's (2002) "level of usage" measures. The Pearson correlation analysis on the five measures indicated that not all measures were significantly positively correlated with each other. The resulting Cronbach's Alpha was relatively low at 0.71 . Deleting the measures not significantly correlated with the other measures netted a total of three measures. The Cronbach's Alpha of these three measures was 0.78. As a result, these three measures were summed into a single scale and used for statistical analysis.

\section{Independent Variables - TAM}

The TAM measures of 'perceived usefulness' were adapted from Davis' (1989) seminal work. All six items are significantly positively correlated with each other. The resulting Cronbach's Alpha of 0.96 allowed for a summation the measures into a single index for statistical testing purposes.

The measures for 'attitude' were adapted from a combination of Karahanna et al. (1999) and Al-Gahtani (2001), which were both based on Ajzen and Fishbein's (1980) Theory of Reasoned Action. All five were significantly positively correlated with each other. The Cronbach's Alpha of 0.92 was high enough for a summation of the items into a single index for statistical testing. 


\section{Independent Variables -Absorptive Capacity}

The absorptive capacity measures were indicative of the ease of learning XBRL. As previously discussed, the easier a firm believes it is to learn XBRL (as the CD technology example), the more they would be willing to accept/adopt it. The six measures were adapted from a combination of Link and Siegel (2002) and Malhotra et al. (2005). All six measures were significantly positively correlated with each other. Similar to the TAM measures, the Cronbach's Alpha for 'perceived ease of learning' of 0.96 was high enough for a summation of the measures into a single index for statistical testing.

\section{RESULTS}

Since both business professionals and MBA students responded similarly with regard to the dependent variable, and they were both low in previous XBRL knowledge and experience, they were collapsed into a single group for statistical testing purposes ${ }^{6}$. All three research hypotheses were tested using linear regression analysis ${ }^{7}$. A conservative alpha of 0.05 was used for significance. Table 2, panel A (for TAM) and panel B (for absorptive capacity), summarizes the regression results.

\section{Hypotheses 1 and 2}

Hypotheses 1 and 2 represented the TAM-based analysis and predicted that XBRL adoption would occur if the decision maker perceived XBRL to be highly useful in the job and if the decision maker had a favorable attitude toward technology ${ }^{8}$. As hypothesized, the standardized beta coefficient for the summed 'perceived usefulness' measure was positive and significant (beta $=0.36$, p-value $<0.01)$. The more useful XBRL was perceived, the higher the intent to adopt. A ttest indicated the summated mean for 'perceived usefulness' was significantly higher than the midpoint of the scale (higher scores refer to more useful; t-statistic

\footnotetext{
${ }^{6}$ T-tests were conducted for both XBRL knowledge and experience between samples. There were no statistical differences found ( $\mathrm{p}$-value $>0.10)$.

7 The demographic covariates (i.e., age, gender, and years of work experience) were initially added to the regressions. None were significant at an alpha of 0.05. Thus, none were included in the final analyses.

${ }^{8}$ The measures used for 'Attitude' were general in nature. Therefore, the "attitude towards XBRL" portion of the hypothesis is presumed implicit, given the context of the entire survey.
} 
$=5.27, \mathrm{p}$-value <0.01). Therefore, the sample, on average, perceived XBRL to be useful in their jobs. Additionally, this variable explains approximately $17 \%$ of the variation.

The results for 'attitude' were not as supportive. Even though the standardized beta coefficient for 'attitude' was negative as predicted (a low score on the summed 'attitude' measure represented a favorable attitude toward technology), it was not significant (beta $=-0.17, \mathrm{p}$-value $=0.11$ ). However, $\mathrm{t}$-test results indicated that the sample, on average, had favorable attitudes toward technology $(\mathrm{t}$-statistic $=$ -23.44, p-value $<0.01)$.

In summary, there was some evidence supporting hypothesis 1 , but not for hypothesis 2 . The differential findings are unique to the TAM literature. A potential reason for the non-significant 'attitude' result could be that the measures did not specifically mention XBRL (see footnote 8 ) $^{9}$. Even though the combined sample was favorable toward technology in general, it may not have been favorable toward XBRL specifically.

\section{Hypotheses 3}

Hypothesis 3 represented the absorptive capacity-based analysis and predicted that absorptive capacity levels would be positively related to the decision to adopt XBRL. Thus, the higher the absorptive capacity for a firm, the more likely they will adopt XBRL. The regression results provide some evidence supporting this hypothesis ${ }^{10}$. Specifically, the standardized beta coefficient is positive and significant (beta $=0.27, \mathrm{p}$-value $=0.02$ ). Approximately $6 \%$ of the variation is explained. The result of a t-test confirmed that the sample, on average, thought XBRL was relatively easy to learn, since their mean was significantly higher than the midpoint of the summed scale (a higher score represented XBRL was perceived easy to learn; t-statistic $=6.93$, p-value $<0.01$ ).

\footnotetext{
${ }^{9}$ Consistent with Davis (1989), multicollinearity effects can be ruled out since the standard errors of the estimates are low ( 0.04 for 'perceived usefulness' and 0.07 for 'attitude').

${ }^{10}$ No violations of the assumptions were found for any regressions run.
} 


\begin{tabular}{|c|c|c|c|c|}
\hline \multicolumn{5}{|c|}{$\begin{array}{c}\text { Panel A } \\
\text { TAM-Based Regression }\end{array}$} \\
\hline Independent Variables & $\begin{array}{l}\text { Beta } \\
\text { Coefficient }\end{array}$ & $T$-Statistic & $P$-Value & $\begin{array}{c}\text { Adjusted } \\
\mathrm{R}^{2}\end{array}$ \\
\hline $\begin{array}{l}\text { Perceived Usefulness } \\
\text { Attitude }\end{array}$ & $\begin{array}{r}0.36 \\
-0.17\end{array}$ & $\begin{array}{c}3.42 \\
-1.63\end{array}$ & $\begin{array}{r}<0.01 \\
0.11\end{array}$ & 0.17 \\
\hline \multicolumn{5}{|c|}{$\begin{array}{c}\text { Panel B } \\
\text { Absorptive Capacity-Based Regression }\end{array}$} \\
\hline Independent Variable & $\begin{array}{l}\text { Beta } \\
\text { Coefficient }\end{array}$ & $T$-Statistic & $P$-Value & $\begin{array}{c}\text { Adjusted } \\
\mathrm{R}^{2}\end{array}$ \\
\hline Ease of Learning & 0.27 & 2.42 & 0.02 & 0.06 \\
\hline
\end{tabular}

Table 2. Regression Results for TAM and Absorptive Capacity's Effect on XBRL Adoption Intentions (Hypotheses 1-3)

\section{CONCLUSIONS}

Pinsker (2007) presented a conceptual framework outlining potential theories for the explanation of management's XBRL adoption intentions (in a continuous disclosure context). The current study provided some empirical evidence supporting two of three hypotheses, which were based on Pinsker's framework (thus validating part of the framework). The results indicate that both the TAM and absorptive capacity represent appropriate theories for studying XBRL adoption. Ttests showed participants believed XBRL would be relatively easy to learn for their jobs (absorptive capacity); it was useful for their jobs (TAM), and they had favorable attitudes toward technology in general (TAM). However, future related TAM research should be conducted either with a modified 'attitude' variable or through eliminating this variable altogether (adjusted R2 drops slightly to $15 \%$ without 'attitude'). 
"The rate at which innovations are adopted by firms constitutes an important part of the process of technological change (Hannan and McDowell $(1984,328)$." The SEC, AICPA, "Big 4" CPA firms, and XBRL International members, among other global constituencies, are interested in the reasons why firms may or may not adopt XBRL. Understanding these reasons could go a long way into forecasting which firms ultimately adopt XBRL when it is not mandated, as well as which firms are more "accepting" to the idea of continuous disclosure. Firms whose managers are less knowledgeable about technology are even more intriguing to study, because their actions related to IT adoption are not as predictable as managers' behavior in high technology firms (i.e., first movers). This study's findings add to the existing practical and academic research regarding perceived benefits of XBRL adoption for firms (i.e., Bonson (2001); Pinsker and Wheeler (2003); Pinsker and Li (forthcoming)). Additionally, the statistical tests used were more powerful than the previous qualitative absorptive capacity study (Link and Siegel 2002).

An interesting finding was the difference in significance between 'perceived usefulness' and 'attitude. No other TAM-related research has found this mismatch. In this initial stage of XBRL adoption, the evidence indicates that perhaps XBRL adoption research is unique from previous IT adoption research? The results also represent a beginning to the investigation of firm-specific characteristics that could influence CD technology adoption. Future research should expand this stream.

This study only produced evidence relevant to boxes one and three on Pinsker's (2007) framework. Future researchers may want to obtain samples with different levels of XBRL knowledge and experience or from different locales throughout the U.S. for the same boxes or find samples from relation-based countries (i.e., boxes two and four). If the latter choice is made, researchers could investigate additional macro variables, such as culture, that could impact the adoption decision. Since CD is expected to occur on a global scale (due to regulatory changes), such relation-based country adoption knowledge would be valuable information for multiple parties (e.g., international regulators, stockholders, software companies, etc.).

This study is subject to limitations inherent with a survey methodology. For example, since there were no performance incentives, the participants may not have provided their best effort in considering their responses. Further, since some 
of the sample was MBA students, evaluation apprehension effects (i.e., participants behaving in a way as to please the researcher, rather than their "true beliefs) cannot be ruled out, although, the survey was conducted anonymously for all participants.

\section{REFERENCES}

AJZEN, I.; FISHBEIN, M. (1980). Understanding Attitudes and Predicting Social Behavior. Englewood Cliffs, NJ: Prentice-Hall.

AL-GAHTANI, S. (2001): "The applicability of TAM outside North America: An empirical test in the United Kingdom", Information Resources Management Journal, vol.14 (3): 37-46.

ATTEWELL, P.; RULE, J. (1984): "Computing and organizations: What we know and what we don't know", Communications of the ACM, vol.27: 1184-1192.

BONSÓN, E. (2001): "The role of XBRL in Europe", International Journal of Digital Accounting Research, vol.1 (2): 101-110.

COHEN, W. M.; LEVINTHAL, D. A. (1990): "Absorptive capacity: A new perspective on learning and innovation", Administrative Science Quarterly, vol.35: $128-152$.

DAVIS, F. D. (1989): "Perceived usefulness, perceived ease of use, and user acceptance of information technology", MIS Quarterly, vol.13 (3): 319-340.

DAVIS, F.D. (1993): "User acceptance of information technology: System characteristics, user perceptions and behavioral impacts", International Journal of Man-Machine Studies, vol.38: 475-487.

FICHMAN, R. G. (1992): "Information technology diffusion: A review of empirical Research", Proceedings of the $13^{\text {th }}$ International Conference on Information Systems (ICIS): 195-206.

GEORGE, G.; ZAHRA, S. A.; WHEATLEY, K. K.; KHAN, R. (2001): “The effects of alliance portfolio characteristics and absorptive capacity on performance: A study of biotechnology firms", Journal of High Technology Management Research, vol.12: 205-226. 
HANNAN, T. H.; MCDOWELL, J. M. (1984): "The determinants of technology adoption: The case of the banking firm", Rand Journal of Economics, vol.15 (3): 328-335.

HODGE, F. D., KENNEDY, J. J.; MAINES. L. A. (2004): Does search-facilitating technology improve the transparency of financial reporting?, The Accounting Review, vol.79 (3): 687-703.

HUNTON, J.; WRIGHT, A.; WRIGHT, S (2003). The supply and demand for continuous reporting. In: S. Roohani, ed. Trust and Data Assurances in Capital Markets: The Role of Technology Solutions. Smithfield, RI: Pricewaterhouse Coopers: 7-16.

KARAHANNA, E.; STRAUB, D.W.; CHERVANY, N.L. (1999): "Information technology adoption across time: A cross-sectional comparison of pre-adoption and post-adoption beliefs", MIS Quarterly, vol.23 (2): 183-213.

KIM, L. (1998): "Crisis construction and organizational learning: Capability building in catching-up at Hyundai”, Organization Science, vol.9: 506-521.

KOZA, M. P.; LEWIN, A. Y. (1998): "The co-evolution of strategic alliances", Organization Science, vol. 9: 255-264.

LI, S.; PARK, S. H. (2004): "The great leap forward: The transition from relationbased governance to rule-based governance", Organizational Dynamics, vol.33 (1): 63-78.

LINK, A. N.; SIEGEL, D. S. (2002): "Unions and technology adoption: A qualitative analysis of the use of real-time control systems in U.S. coal firms", Journal of Labor Research, vol.23 (4): 615-630.

MALHOTRA, A.; GOSAIN, S.; EL SAWY, O. A. (2005): “Absorptive capacity configurations in supply chains: Gearing for partner-enabled market knowledge creation", MIS Quarterly, vol.29 (1): 145-187.

PINSKER, R. (2007): A theoretical framework for examining the corporate adoption decision involving XBRL as a continuous disclosure reporting technology. In: R. Debreceny, C. Felden, and M. Piechocki, ed. New Dimensions of Business Reporting and XBR,. Springer Group: Verlag, Germany: 73-98. 
PINSKER, R.; LI, S. (2008): "Costs and benefits of XBRL adoption: Early evidence", Communications of the ACM, vol.51 (3): 47-50.

PINSKER, R; WHEELER, P. (2009): "The effects of expanded independent assurance on the use of firm-initiated disclosures by investors with limited business knowledge", Journal of Information Systems, (forthcoming Spring 2009).

STOCK, G. N.; GREIS, N. P.; FISCHER, W. A. (2001): "Absorptive capacity and new product development", Journal of High Technology Management Research, vol.12: 77-91.

SEC (2002): The Sarbanes-Oxley Act. United State Securities and Exchange Commission. Washington DC. 